\title{
Ethical aspects of obstetric care: expectations and experiences of patients in South East Nigeria
}

\author{
This article was published in the following Dove Press journal: \\ International Journal of Women's Health \\ 5 September 2013 \\ Number of times this article has been viewed
}

\section{Chukwuemeka A lyoke' \\ Frank O Ezugwu ${ }^{2}$ \\ George O Ugwu' \\ Osaheni L Lawani ${ }^{3}$ \\ Azubuike K Onyebuchi ${ }^{3}$ \\ 'Department of Obstetrics and Gynaecology, University of Nigeria Teaching Hospital, Enugu, Nigeria; \\ ${ }^{2}$ Department of Obstetrics and Gynaecology, Enugu State University \\ Teaching Hospital, Enugu, Nigeria; \\ ${ }^{3}$ Department of Obstetrics and \\ Gynaecology, Federal Medical Centre, \\ Abakaliki, Nigeria}

Correspondence: Chukwuemeka A lyoke Department of Obstetrics and Gynaecology, University of Nigeria Teaching Hospital, Ituku-Ozalla, PO Box 4998, Enugu Headquarters, Enugu, Nigeria

Email caiyoke@yahoo.co.uk
Background: Medical ethics is not given due priority in obstetric care in many developing countries, and the extent to which patients value compliance with ethical precepts is largely unexplored.

Objective: To describe the expectations and experiences of obstetric patients in South East Nigeria with respect to how medical ethics principles were adhered to during their care.

Methods: This was a cross-sectional, questionnaire-based study involving parturient women followed in three tertiary hospitals in South East Nigeria.

Results: A total of 1,112 women were studied. The mean age of respondents was $29.7 \pm 4.1$ years. Approximately $98 \%$ had at least secondary education. Ninety-six percent considered ethical aspects of care as important. On the average, over $75 \%$ of patients expected their doctors to comply with the different principles of medical ethics and specifically, more than $76 \%$ of respondents expected their doctors to comply with ethical principles related to information and consent during their antenatal and delivery care. There was a statistically significant difference between the proportions of women who expected compliance of doctors with ethical principles and those who did not $(P<0.001)$. Multivariate analysis showed that increasing levels of skilled occupation (odds ratio [OR] 9.35, $P<0.001$ ), and residence in urban areas (OR 2.41, $P<0.001)$ increased the likelihood of patients expecting to be informed about their medical conditions and their opinions being sought. Although the self-reported experiences of patients concerning adherence to ethical principles by doctors were encouraging, experiences fell short of expectations, as the level of expectation of patients was significantly higher than the level of observed compliance for all the principles of medical ethics.

Conclusion: The level of practice of medical ethics principles by doctors during obstetric care in South East Nigeria was encouraging but still fell short of the expectations of patients. It is recommended that curriculum-based training of doctors and medical students should be implemented, and hospital policy makers should do more to promote ethical aspects of care, by providing official written guidelines for adherence to medical ethical principles during obstetric care.

Keywords: medical ethics, obstetric care, principles

\section{Introduction}

Despite the existence of a code of medical ethics published by the regulatory authority for Medical Ethics in Nigeria (the Medical and Dental Council of Nigeria), there is practically no formal curriculum-based training for doctors and medical students on medical ethics. ${ }^{1}$ Empirical observations suggest that the observance of ethical precepts by health workers is often a matter of individual attitude to work, rather than compliance with enacted rules. Communication between doctor and patient is 
still heavily driven by the doctor, and patient participation often depends entirely on prompting by the doctor. This attitude to medical ethics has festered unabated, mainly because of many other overarching factors related to the provision, access, and utilization of medical care in developing countries. ${ }^{2}$

First among these concerns is the unavailability of adequate manpower and resources for health care, resulting in many health facilities and communities being under served. ${ }^{2}$ Added to this, there are cultural inhibitions and widespread ignorance among the populace, especially on health issues, resulting in poor utilization of many rural health facilities, the inability of patients to assert their rights to free communication with their doctors, ${ }^{3}$ and the possibility of the misinterpretation (by patients and their relations) of western-style informed consent practices as evidence that the doctor "does not know what to do." "Besides these, there are also high population-to-doctor ratios, which result in work overload for doctors.

In the midst of these scenarios, it has become debatable whether it is worthwhile to promote western-style medical ethics in developing countries, where basic health care is still not available to many. ${ }^{2}$ Consequently, medical ethics is evolving rather slowly in Nigeria, and even physicians are unsure of the direction it should take. ${ }^{5}$ For instance, approximately $73 \%$ of surgeons surveyed in a recent study in Nigeria agreed that informed consent "was alien to the African psyche." There remains substantial doubt about whether western-style medical ethics practices are sustainable in Africa, given the cultural and socioeconomic differences between the two societies. $^{2,4-7}$

In relation to obstetrics practice, anecdotal evidence shows that many patients feel that they are not treated with respect and dignity in many public hospitals in Nigeria, reinforcing the existence of inadequate attention of health workers to the ethical aspects of care. The current high rate of patronage of unskilled providers for antenatal and delivery care in Nigeria appears to be fanned, at least in part, by a lack of trust in public hospitals. The prevalent high maternal mortality rates in Nigeria are blamed largely on the low rate of deliveries attended by skilled attendants. ${ }^{8}$ Promoting respectful and dignified treatment could therefore be useful in addressing the problem of poor utilization of skilled attendants in public hospitals. ${ }^{9}$

We found scant literature on the ethical aspects of obstetric care in Nigeria. ${ }^{10-13}$ In order to contribute to the debate on whether medical ethics should be emphasized in developing countries, we sought to explore patients' perspectives on the observance and practice of ethical precepts during obstetric care. The aims of this study were therefore to describe patients' expectations and experiences of the ethical conduct of their physicians during obstetric care in three university teaching hospitals in South East Nigeria.

\section{Methods}

\section{Study area/centers}

South East Nigeria is made up of five states and has a combined population of about 20 million, based on the 2006 Nigeria national census. ${ }^{14}$ The area is served by ten tertiary teaching hospitals. The study took place at three of these centers in Enugu and Ebonyi states namely, the University of Nigeria Teaching Hospital Enugu; the Federal Medical Centre, Abakaliki, Ebonyi State; and the Enugu State University Teaching Hospital, Enugu. These hospitals cater to a combined population of about 5 million urban and rural dwellers.

\section{Study population}

The study population included parturient women who had antenatal care and/or delivery at the study hospitals during the study period. The obstetric clients in these hospitals are usually self-referred, pregnant women who desire to receive care under specialist obstetricians and/or in a facility with modern facilities for obstetric care, and women with complicated pregnancies who have been referred from surrounding lower-level health facilities. In all three hospitals, women who had normal deliveries were usually observed in the hospital for 48 hours before discharge, while those that had cesarean delivery were usually discharged on the fifth to seventh postoperative day.

\section{Study period}

The study covered the period from July 1, 2010 to June 30, 2011 .

\section{Study design}

This was a cross-sectional, questionnaire-based study involving booked parturient women followed in three tertiary maternity hospitals in South East Nigeria.

\section{Sampling technique}

A convenience sample of the three teaching hospitals was selected from the eleven teaching hospitals in the South East geopolitical zone of Nigeria. Sampling of study participants was purposive and involved enrolment of consecutive consenting women who delivered during the study period. 


\section{Data collection}

In each of the three selected hospitals, 500 consecutive consenting women who delivered during the study period were administered anonymized, semistructured, pretested questionnaires developed for the study. The questionnaires were self-administered when the woman was sufficiently literate to understand it or otherwise, were interviewer-administered. For literate patients, the questionnaire was administered in the English language, whereas for semiliterate women, the questionnaire was administered by the interviewer, in the Igbo language. The questions were based on their experiences in the "index" pregnancy. The questionnaire was organized in three parts, with the first two parts involving open-ended questions. The first part dwelt on obstetric and demographic data, while the second part explored what the women perceived to be ethical misconduct and their expectations regarding the practice of ethical principles by doctors; the third part contained closed-ended questions that elicited the experiences of patients concerning how their doctors observed specific aspects of the ethical principles of autonomy, justice, beneficence, and nonmaleficence. ${ }^{15}$ The questionnaire was designed to yield semiquantitative data, with participants' responses recorded on binary (Yes/ No) or Likert scales. For patients who had uncomplicated vaginal deliveries, the questionnaire was administered on the second postpartum day, whereas for those that had cesarean delivery, it was administered on the fifth postpartum day (Supplementary figure).

\section{Data analysis}

The statistical analysis was done using SPSS statistical software version 17.0 for Windows (SPSS Inc., Chicago, IL, USA), using descriptive and inferential statistics. We related the conduct that patients expected or experienced from doctors to medical ethics principles and then interpreted which ethical principle each behavior represented. The main outcome measures were the proportions of respondents who expected specified ethical behaviors by their doctors and the proportions of women who experienced or observed compliance with ethical principles. The frequencies of different responses were expressed as percentages. Tests of significance for the differences between categorical variables were done with the Chi-square test. Bivariate logistic regression was used to determine the predictability of the expectations of patients. Those who expected compliance were coded as "Yes" (1), while those who did not were coded as "No" (0). The results were reported as adjusted odds ratios and $95 \%$ confidence intervals. A $P$-value $\leq 0.05$ was considered significant.

\section{Ethical clearance}

Ethical clearance for the study was obtained from the Research Ethics Committees of the three hospitals.

\section{Results}

A total of 1,500 questionnaires were distributed, out of which 1,420 were returned. Of these, $1,112(74.1 \%)$ were fully completed, and these were used for analysis. A total of 320 of the 1,112 respondents were from University of Nigeria Teaching Hospital, 309 from the Federal Medical Centre Abakaliki, while 483 were from the Enugu State University Teaching Hospital.

\section{Sociodemographic characteristics}

The mean age of respondents was $29.7 \pm 4.1$ years. Approximately $98 \%$ had at least secondary education, with about $58 \%$ possessing a postsecondary certificate. Table 1 shows

Table I The demographic and obstetric characteristics of respondents

\begin{tabular}{|c|c|c|}
\hline Characteristic & Frequency & Percentage \\
\hline \multicolumn{3}{|l|}{ Age (years) } \\
\hline $10-20$ & 16 & 1.4 \\
\hline $21-30$ & 696 & 62.6 \\
\hline $31-40$ & 390 & 35.1 \\
\hline $4 I-50$ & 10 & 0.9 \\
\hline \multicolumn{3}{|l|}{ Occupational group } \\
\hline Unemployed/students & 416 & 37.4 \\
\hline Low-skilled/crafts/traders & 136 & 12.2 \\
\hline Civil servants (nonprofessional) & 440 & 39.6 \\
\hline $\begin{array}{l}\text { Middle-level professionals (nurses, } \\
\text { laboratory scientists, etc) }\end{array}$ & 80 & 7.2 \\
\hline Upper-level professionals & 40 & 3.6 \\
\hline \multicolumn{3}{|l|}{ Educational status } \\
\hline No formal education & 16 & 1.4 \\
\hline Primary education & 16 & 1.4 \\
\hline Secondary education & 440 & 39.6 \\
\hline Tertiary or post-tertiary education & 640 & 57.6 \\
\hline \multicolumn{3}{|l|}{ Religion } \\
\hline Christian & 1,104 & 99.3 \\
\hline Roman Catholic & 680 & 61.2 \\
\hline Non-Catholic & 432 & 38.8 \\
\hline Non-Christian & 8 & 0.7 \\
\hline \multicolumn{3}{|l|}{ Tribe } \\
\hline Igbo & 1,064 & 95.7 \\
\hline Non-Igbo & 48 & 4.3 \\
\hline \multicolumn{3}{|l|}{ Residence } \\
\hline Urban & 920 & 82.7 \\
\hline Rural & 192 & 17.3 \\
\hline \multicolumn{3}{|l|}{ Parity } \\
\hline Primipara & 408 & 36.7 \\
\hline Multipara & 656 & 59.0 \\
\hline Grand multipara & 48 & 4.3 \\
\hline \multicolumn{3}{|l|}{ Route of delivery } \\
\hline Vaginal & 960 & 86.3 \\
\hline Abdominal & 152 & 13.7 \\
\hline
\end{tabular}


the demographic and obstetric characteristics of the respondents.

\section{Expectations of obstetric patients and factors that predict expectations}

Approximately 89\% $(990 / 1,112)$ of respondents considered free communication between doctors and patients as a very important aspect of care, and 80\% $(890 / 1,112)$ of respondents stated that the conduct of doctors and other health workers was an important consideration that informed their choice of where to receive maternity care. On a six-point scale, $66 \%(734 / 1,112)$ considered ethical aspects of care as very important, $20 \%(222 / 1,112)$ as moderately important, $10 \%$ $(111 / 1,112)$ as important, and 4\% $(45 / 1,112)$ as unimportant; no woman considered respectful and dignified treatment as moderately unimportant or very unimportant.

Table 2 summarizes the distribution of respondents, based on the ethical practices they expected from doctors. Approximately $78 \%(867 / 1,112)$ expected to be fully informed about their conditions, while 76\% $(845 / 1,112)$ expected their opinions and consent to be sought for investigations and treatment that they were to undergo.

Table 3 summarizes the results of bivariate logistic regression to determine which patient characteristics

Table 2 The comparison of the numbers of patients who expected compliance with ethical principles by their doctors

\begin{tabular}{|c|c|c|}
\hline \multirow[t]{2}{*}{ Ethical conduct } & \multicolumn{2}{|c|}{$\begin{array}{l}\text { Number of patients } \\
(\mathrm{n}=1, \mathrm{I} \mid \mathrm{I})\end{array}$} \\
\hline & $\begin{array}{l}\text { Those who } \\
\text { expected (\%) }\end{array}$ & $\begin{array}{l}\text { Those who } \\
\text { did not } \\
\text { expect (\%) }\end{array}$ \\
\hline Provision of adequate privacy & $912(82.0)$ & $200(18.0)$ \\
\hline $\begin{array}{l}\text { Provision of information on diagnosis } \\
\text { and the options of management } \\
\text { available based on current evidence }\end{array}$ & $872(78.6)$ & $240(2 \mathrm{I} .4)$ \\
\hline $\begin{array}{l}\text { Seeking patient's opinion and consent } \\
\text { on options in the investigation } \\
\text { or treatment to be undertaken }\end{array}$ & $848(76.3)$ & $264(23.7)$ \\
\hline $\begin{array}{l}\text { Regular and punctual attendance } \\
\text { at clinics by doctors }\end{array}$ & I, 109 (99.7) & $3(0.3)$ \\
\hline $\begin{array}{l}\text { Fairness in the order of attendance } \\
\text { to patients ("first come, first seen," } \\
\text { except for medical emergencies) }\end{array}$ & I, $102(99.1)$ & $10(0.9)$ \\
\hline $\begin{array}{l}\text { Consideration of the ability of patients } \\
\text { to pay for drugs or services, by } \\
\text { exploring options based on necessity, } \\
\text { efficacy, and cost }\end{array}$ & $996(89.6)$ & $116(10.4)$ \\
\hline $\begin{array}{l}\text { Respecting patient's feelings, including } \\
\text { religious beliefs of patients during } \\
\text { clinical evaluation and when } \\
\text { recommending management options }\end{array}$ & $616(55.4)$ & $498(44.6)$ \\
\hline
\end{tabular}

predicted the type of expectation of patients, with respect to autonomy-related conduct. Occupation, age, residence, and religious denomination were all predictors of patients who would expect information and consent for investigations and treatment plans. Increasing levels of skilled occupation and residence in urban areas increased the likelihood of patients expecting to be informed about their medical conditions and their opinions being sought. However, increasing age and being Roman Catholic decreased the likelihood. Educational level, parity, mode of delivery, and tribal group were not significant predictors of the likelihood of expecting to have information and having the patient's consent sought.

With respect to the expectation of justice-related conduct, being a low skilled worker, age, residence, and tribe were significant predictors of the expectations of the patient. Low-skilled occupation, urban residence, and being of the Igbo tribe increased the likelihood of a patient's expectation that the doctor give consideration for their ability to pay for investigations and treatment, while increasing age decreased the likelihood. Educational status, being a Catholic (or not), parity, and mode of delivery did not have a statistically significant ability to predict the expectation of women with respect to justice-related conduct.

\section{Patients' experiences of medical ethics practices of their doctors}

The distribution of patients based on their experiences with respect to the medical ethics practices of doctors is summarized in Table 4. Approximately $78.4 \%(872 / 1,112)$ of respondents reported experiencing at least one instance where the doctor's conduct could be interpreted as a failure to comply with medical ethics principles, in the course of their care in the index pregnancy.

\section{Informed consent for cesarean section}

One hundred and fifty-two women who had a cesarean section responded to questions about their experiences with the process of obtaining their consent for surgery. Of these, 124 had a primary cesarean section, while 28 had a repeat cesarean section. For 36 women (23.7\%), the consent was signed by the woman's husband, and all of these cases were for emergency cesarean sections. Table 5 summarizes the content of the informed consent for cesarean section, as reported by patients.

\section{Comparison of expectations with experiences}

Table 6 summarizes the comparison of expectations with the experiences of patients, with respect to the medical ethics 
Table 3 Results of the binary logistic regression for predicting the expectation of patients, with respect to the compliance of doctors with ethical principles

\begin{tabular}{|c|c|c|c|c|c|c|}
\hline \multirow[t]{2}{*}{ Variable } & \multicolumn{3}{|c|}{ Expectation of information and asking for opinion } & \multicolumn{3}{|c|}{ Expectation of consideration of cost } \\
\hline & $\begin{array}{l}\text { Odds } \\
\text { ratio }\end{array}$ & $\begin{array}{l}95 \% \text { Confidence } \\
\text { interval }\end{array}$ & $P$-value & $\begin{array}{l}\text { Odds } \\
\text { ratio }\end{array}$ & $\begin{array}{l}95 \% \text { Confidence } \\
\text { interval }\end{array}$ & $P$-value \\
\hline \multicolumn{7}{|l|}{ Occupation } \\
\hline Professionals & 9.35 & $3.57-25.94$ & $<0.00 I^{*}$ & 1.73 & $0.68-4.40$ & 0.25 \\
\hline Midlevel professionals & 5.39 & $1.83-15.9 \mid$ & $<0.00 I^{*}$ & 2.14 & $0.79-5.78$ & 0.13 \\
\hline Civil servants & 3.01 & $1.91-9.16$ & $0.05^{*}$ & 2.38 & $0.82-6.91$ & 0.10 \\
\hline Low-skilled workers & 3.43 & $1.15-10.23$ & $0.03 *$ & 3.53 & $1.3-9.5$ & $0.01 *$ \\
\hline \multicolumn{7}{|l|}{ Unemployed $^{\circ}$} \\
\hline Age & 0.86 & $0.81-0.92$ & $<0.001 *$ & 0.91 & $0.86-0.96$ & $<0.00 I^{*}$ \\
\hline \multicolumn{7}{|l|}{ Residence } \\
\hline Urban & 2.41 & $1.56-3.72$ & $<0.001 *$ & 1.49 & $1.02-2.15$ & $0.04 *$ \\
\hline \multicolumn{7}{|l|}{ Rural $^{\circ}$} \\
\hline \multicolumn{7}{|l|}{ Christian denomination } \\
\hline Catholic & 0.32 & $0.24-0.43$ & $<0.000 *$ & 1.23 & $0.94-1.63$ & 0.13 \\
\hline \multicolumn{7}{|l|}{ Non-Catholic ${ }^{\circ}$} \\
\hline \multicolumn{7}{|l|}{ Education } \\
\hline Tertiary and above & 0.00 & 0.00 & 1.00 & 0.00 & 0.00 & 1.00 \\
\hline Secondary & 0.00 & 0.00 & 1.00 & 0.00 & 0.00 & 1.00 \\
\hline Primary & 0.28 & $0.91-0.86$ & $0.03 *$ & 0.29 & $0.19-1.15$ & 1.13 \\
\hline No formal education ${ }^{\circ}$ & 0.98 & $0.70-1.35$ & 0.88 & 0.14 & $0.93-1.69$ & 2.17 \\
\hline \multicolumn{7}{|l|}{ Parity } \\
\hline Multiparous & 0.82 & $0.55-1.13$ & 0.22 & 0.75 & $0.56-1.01$ & 0.06 \\
\hline \multicolumn{7}{|l|}{ Nulliparous $^{\circ}$} \\
\hline \multicolumn{7}{|l|}{ Mode of delivery } \\
\hline Vaginal & 1.35 & $0.85-2.14$ & 0.21 & 0.81 & $0.53-1.21$ & 0.30 \\
\hline \multicolumn{7}{|l|}{ Cesarean $^{\circ}$} \\
\hline \multicolumn{7}{|l|}{ Tribal group } \\
\hline lgbo & 0.00 & 0.00 & 0.90 & 3.48 & $1.52-7.96$ & $<0.00 I^{*}$ \\
\hline Non-lgbo ${ }^{\circ}$ & & & & & & \\
\hline
\end{tabular}

Notes: *Statistically significant $P$-value; ${ }^{\circ}$ reference independent variable.

Table 4 Comparison of the experiences of women concerning medical ethics practices

\begin{tabular}{|c|c|c|c|}
\hline \multirow[t]{2}{*}{ Obstetrician conduct } & \multicolumn{2}{|c|}{$\begin{array}{l}\text { Number of patients who experienced conduct (\%) } \\
n=I, I I 2\end{array}$} & \multirow[t]{2}{*}{$P$-value } \\
\hline & Yes & No & \\
\hline Appropriate autonomy-related conduct & & & $<0.00 I^{*}$ \\
\hline Adequate privacy & $624(56.1)$ & $488(43.9)$ & \\
\hline Examination in the presence of a chaperone & $504(45.3)$ & $608(54.7)$ & \\
\hline Explanation of diagnosis and treatment options & $772(69.4)$ & $340(30.6)$ & \\
\hline $\begin{array}{l}\text { Seeking opinion and consent of patients on options } \\
\text { of investigation and treatment }\end{array}$ & $656(59.0)$ & $356(4 I .0)$ & \\
\hline Beneficence-related conduct & & & $<0.00 I^{*}$ \\
\hline Punctuality to antenatal clinic & $389(35.0)$ & $723(65.0)$ & \\
\hline Regular attendance to antenatal clinic & $612(55.0)$ & $500(45.0)$ & \\
\hline Caring attitude & $1,036(93.0)$ & $76(7.0)$ & \\
\hline Justice-related conduct & & & $<0.00 I^{*}$ \\
\hline Consideration of cost of investigations and drugs & $663(59.6)$ & $449(40.4)$ & \\
\hline $\begin{array}{l}\text { No favoritism in attending to patients (patients seen } \\
\text { on a "first come, first seen" basis) }\end{array}$ & $468(42.1)$ & $644(57.9)$ & \\
\hline Nonmaleficence-related conduct & & & $<0.00 I^{*}$ \\
\hline Verbal abuse & $48(4.3)$ & $\mathrm{I}, 064(95.7)$ & \\
\hline Verbal sexual overtures & $32(2.9)$ & $\mathrm{I}, 080(97.1)$ & \\
\hline Demand for financial gratification & $48(4.3)$ & $\mathrm{I}, 064(95.7)$ & \\
\hline Inappropriate touching & $72(6.5)$ & $\mathrm{I}, 040(93.5)$ & \\
\hline Participation in strike actions & I,045 (94.0) & $67(6.0)$ & \\
\hline
\end{tabular}

Notes: The comparison was based on Chi-square test of significant difference. *Statistically significant $P$-value. 
Table 5 Self-reported content of counseling for cesarean section

\begin{tabular}{|c|c|c|}
\hline \multirow[t]{2}{*}{ Content of counseling for informed consent } & \multicolumn{2}{|c|}{ Number of women who had counseling } \\
\hline & $\begin{array}{l}\text { Emergency cesarean } \\
n=100(\%)\end{array}$ & $\begin{array}{l}\text { Elective cesarean } \\
\mathbf{n}=\mathbf{5 2}(\%)\end{array}$ \\
\hline \multicolumn{3}{|c|}{ Detailed explanation of the indication for cesarean section } \\
\hline Yes & $15(15.0)$ & 52 \\
\hline No & $85(85.0)$ & 0 \\
\hline \multicolumn{3}{|c|}{ Detailed explanation of the short-term-maternal risks associated } \\
\hline \multicolumn{3}{|c|}{ with cesarean delivery, such as anesthetic risks, primary hemorrhage, } \\
\hline \multicolumn{3}{|l|}{ injury to bladder or ureters, infection, and DVT } \\
\hline Yes & $20(20.0)$ & I \\
\hline No & $80(80.0)$ & 51 \\
\hline \multicolumn{3}{|c|}{ Detailed explanation of long-term maternal risks associated } \\
\hline \multicolumn{3}{|c|}{ with cesarean section, such as higher risks for placenta previa and uterine } \\
\hline \multicolumn{3}{|c|}{ rupture in subsequent pregnancies, higher need for subsequent cesarean section } \\
\hline Yes & $10(10.0)$ & 5 \\
\hline No & $90(90.0)$ & 47 \\
\hline \multirow{2}{*}{\multicolumn{3}{|c|}{$\begin{array}{l}\text { Explanation of the surgery itself, including the types of abdominal incision, } \\
\text { duration of surgery, type of anesthesia }\end{array}$}} \\
\hline & & \\
\hline Yes & $0(0.0)$ & 3 \\
\hline No & $100(100.0)$ & 49 \\
\hline \multirow{2}{*}{\multicolumn{3}{|c|}{$\begin{array}{l}\text { Explanation of the process of recovery from surgery, such as pain, } \\
\text { the initial restriction of movement and initial restriction of oral feeding }\end{array}$}} \\
\hline & & \\
\hline Yes & $4(4.0)$ & 0 \\
\hline No & $96(96.0)$ & 45 \\
\hline \multicolumn{3}{|l|}{ Explanation of the costs of surgery } \\
\hline Yes & $3(3.0)$ & 15 \\
\hline No & $97(97.0)$ & 27 \\
\hline
\end{tabular}

Abbreviation: DVT, deep vein thrombosis.

practices of doctors. The expectations of patients differed significantly from their actual experiences with respect to privacy, the provision of information to patients, the solicitation of patients' opinions and consent, regular and punctual attendance to appointments, fairness in attending to patients in clinics (ie, on a "first come, first seen" basis), and consideration of cost when issuing prescriptions.

\section{Rating of doctors' compliance with ethical principles}

Table 7 summarizes patients' rating of the ethical principles practiced by doctors. Favorable rating of the ethical principles practiced by doctors ranged from $41.65 \%$ to $69.4 \%$. The highest rating was for the provision of information to patients, while the lowest rating was that of fairness in the order of attending to patients. Approximately $41 \%$ felt that doctors were poor in obtaining their consent for interventions.

\section{Discussion}

The study shows that an overwhelming proportion of women considered free communication between doctors and patients to be important and that there were significantly greater proportions of respondents who valued and expected their doctors to exhibit conduct in keeping with the cardinal principles of medical ethics ${ }^{13}$ than proportions who did not. This suggests a high level of expectations of ethical practice from doctors. Given the demographics of the studied population, it would therefore appear that among the urban patient population in this developing-country setting, many value the ethical aspects of care.

The remaining discussion of the findings of this study will address the principles of medical ethics enunciated by Beauchamp and Childress. ${ }^{15}$

\section{Patient autonomy}

The ethical principle of patient autonomy determines the appropriate attitude of doctors to foster patients' right to information, primacy in decision making, and confidentiality and privacy. The basic quality of primacy in making decisions is the basis for the requirement of informed consent. ${ }^{2,9,10} \mathrm{In}$ this study, a high proportion of respondents (76\%) expected doctors to explain diagnoses and options of management and to seek their opinions and consent during their care. This is less than the $97 \%$ found by Chung et al, in a study of a nonobstetric inpatients in the US but higher than the $23.9 \%$ found by Cetin et al, in a general patient population in a mili- 
Table 6 Showing the comparison of expectations and the actual experiences of compliance with ethical principles by doctors

\begin{tabular}{|c|c|c|c|}
\hline \multirow[t]{2}{*}{ Ethical conduct } & \multicolumn{2}{|l|}{ Number of patients } & \multirow[t]{2}{*}{$P$-value } \\
\hline & Expected $(n=1,1 \mid 2)$ & Experienced $(n=1,112)$ & \\
\hline Adequate privacy & & & $<0.00 I^{*}$ \\
\hline Yes & 912 & 624 & \\
\hline No & 200 & 488 & \\
\hline $\begin{array}{l}\text { Provide information on diagnosis and the options of management } \\
\text { available based on current evidence }\end{array}$ & & & $<0.00 I^{*}$ \\
\hline Yes & 960 & 772 & \\
\hline No & 152 & 340 & \\
\hline $\begin{array}{l}\text { Seek patient's opinion and consent on the options for investigation } \\
\text { or treatment to be undertaken }\end{array}$ & & & $<0.001 *$ \\
\hline Yes & 948 & 656 & \\
\hline No & 164 & 456 & \\
\hline Regular and punctual attendance at clinics & & & $<0.00 I^{*}$ \\
\hline Yes & 1,109 & 612 & \\
\hline No & 3 & 500 & \\
\hline $\begin{array}{l}\text { Fairness in the order of attendance to patients ("first come, } \\
\text { first seen," except for medical emergencies) }\end{array}$ & & & $<0.00 I^{*}$ \\
\hline Yes & 1,102 & 463 & \\
\hline No & 10 & 649 & \\
\hline Consider the ability of patients to pay for drugs or services & & & $<0.00 I^{*}$ \\
\hline by exploring options, based on necessity, efficacy, and cost & & & \\
\hline Yes & 996 & 636 & \\
\hline No & 116 & 476 & \\
\hline $\begin{array}{l}\text { Respect for patient's feelings, including religious beliefs of patients, } \\
\text { during clinical evaluation and when recommending management options }\end{array}$ & & & $<0.00 I^{*}$ \\
\hline Yes & 616 & 460 & \\
\hline No & 496 & 652 & \\
\hline
\end{tabular}

Note: *Statistically significant $P$-value.

tary hospital in Turkey. ${ }^{16,17}$ The highly selective nature of the patient population in this study might explain this contrast, and it will remain to be seen whether similar findings can be obtainable in the general patient populations.

The study also showed that the proportion of patients who expected adequate information and respect for their opinions was significantly greater than the proportion who acknowledged experiencing these practices. This suggests a gap between expectations and practice and could mean that although the level of ethical practices may be encouraging, doctors need to do more to satisfy the expectations of this patient population. In contrast to a recent survey that showed that surgeons in South West Nigeria considered informed consent to be "alien to African psyche," the findings in this study show that urban women in the South East Nigeria value information and respect for their opinions. The differences in

Table 7 Rating of ethical practices of doctors

\begin{tabular}{|c|c|c|c|c|c|}
\hline \multirow[t]{2}{*}{ Ethical practice } & \multicolumn{5}{|c|}{$\begin{array}{l}\text { Rating } \\
\mathbf{n}=\mathbf{I}, \mathrm{I} \mid \mathbf{2}(\%)\end{array}$} \\
\hline & Excellent & Very good & Good & Poor & Very poor \\
\hline Privacy during interview and examination including use of chaperones & $0(0.0)$ & $24(2.2)$ & $600(54.0)$ & $488(43.8)$ & $0(0.0)$ \\
\hline $\begin{array}{l}\text { Asking your opinion on investigations and treatment before } \\
\text { prescribing them }\end{array}$ & $7(0.6)$ & $63(5.7)$ & $586(52.7)$ & $456(41.0)$ & $0(0.0)$ \\
\hline $\begin{array}{l}\text { Explaining investigations and treatment to you in a way that } \\
\text { you could understand them }\end{array}$ & $10(0.9)$ & $56(5.0)$ & 706 (63.5) & $335(30.1)$ & $5(0.5)$ \\
\hline $\begin{array}{l}\text { Fairness in the order of attendance to patients ("first come, } \\
\text { first seen," except for medical emergencies) }\end{array}$ & $0(0.0)$ & 149 (13.4) & 314 (28.2) & $649(58.4)$ & $0(0.0)$ \\
\hline $\begin{array}{l}\text { Asking if you can pay for chosen test or treatment and offering } \\
\text { you alternatives in case you are not able to pay }\end{array}$ & $0(0.0)$ & II (I.0) & $625(56.2)$ & 473 (42.5) & $3(0.3)$ \\
\hline $\begin{array}{l}\text { Respect for patient's feelings, including religious beliefs of patients, } \\
\text { during clinical evaluation and when recommending management options }\end{array}$ & $30(2.7)$ & $156(14.0)$ & $274(24.6)$ & $612(55.0)$ & $40(3.6)$ \\
\hline
\end{tabular}


the two studies may be due to the study populations (doctors versus pregnant women), but it may also suggest that doctors may need to begin to modify their attitude towards medical ethics in developing societies, like Nigeria.

With respect to the practice of informed consent before a cesarean section, this study found that although efforts were made to obtain consent for both emergency and elective cesarean section, the contents of counseling for such consent appeared to be scanty. In most cases, counseling involved a brief explanation of the indication for the surgery. A previous study of surgical patients in this center alluded to the possibility that scanty content of counseling for surgery might be due to the fear that patients could misinterpret a detailed explanation of risks as a sign that the doctor was incompetent, a throwback to the possibility that patients in this area could easily question the doctors' conduct, including competence. The scanty content of counseling for informed consent defeats the purpose of such counseling, which should be to provide sufficient information for the patient to make up her mind about the procedure. The findings from this study therefore demonstrate the need for the improvement of presurgical counseling during obstetric care in the study centers.

\section{Nonmaleficence}

In this study, the perception by patients that strike actions by doctors constituted ethical misconduct was rife. Similarly, patients perceived lateness to clinics and absence from clinics as ethical misconduct. Whether this conduct constitutes ethical or professional misconduct is debatable. However, the feelings of patients about strike actions need to be taken seriously in view of the need to sustain the patronage of skilled birth attendants by these women. This is necessary to avert recourse to unskilled attendants, which has adverse implications for maternal morbidity and mortality. ${ }^{11}$ That many women go elsewhere to deliver after attending antenatal care in teaching hospitals has severally been attributed to dissatisfaction with health workers' conduct in these teaching centers. Other inappropriate conduct allegedly experienced by pregnant women included verbal abuse, sexual overtures, including inappropriate touching, as well as the demand for financial gratification. Although the proportion of women who experienced these practices ranged from $2 \%-7 \%$, the fact that this inappropriate conduct existed at tertiary levels of care in this country suggests that more needs to be done to protect patients, and one way of doing this is through the enactment of and strict compliance with hospital policies mandating the use of female chaperones for every examination.

\section{Justice}

Justice with respect to obstetric care is related to fair choices regarding investigations and treatment, especially with respect to cost. It can also be related to fairness in attending to patients in clinics, such as seeing patients on a "first come, first seen" basis. The highest proportions of respondents that expected compliance with justice-related ethical principles were, however, found among those who expected doctors to consider cost, efficacy, and their ability to pay for investigations and treatment. This underlines the important place of health care financing in obstetric care in these centers. The ethics of health care financing in developing countries is made more pertinent by the fact that well-structured health insurance schemes either do not exist or are not well developed. Although the recently introduced national health insurance scheme in Nigeria covers antenatal care and normal deliveries, the proportion of the population covered by the insurance scheme is presently very limited.

\section{Predicting patients' expectations}

Although all patients should receive due consideration for the ethical aspects of care, irrespective of their levels of awareness, predicting the specific expectation of patients may assist in laying the appropriate emphases. The study showed that certain demographic features could predict the expectations of patients in this obstetric population. Higher-skilled occupation increased the likelihood of expecting detailed information and informed consent. This may be due to the greater economic and social empowerment of highly skilled workers compared with low-skilled ones. Similarly, residence in urban area also increased this likelihood, perhaps for reasons related to awareness and empowerment. Conversely, increasing age and being Roman Catholic decreased the likelihood that patients would expect their doctors to give them detailed information and also seek their opinions on their management. On its own, increasing level of education had no significant effect on the expectation of detailed information and patients' opinions. These findings are similar to the findings by Chung et al, in the US, that increasing age was a predictor of patients leaving medical decisions to the doctor but is contrary to their findings that university education predicted patients' desire to have more control over their medical decisions. ${ }^{16}$

\section{Strengths and weaknesses of study}

The major strengths of this study include the large sample size and the multicenter design, which broadened the spread 
of respondents and may have enhanced the external validity of the findings. The major drawbacks were the hospital-based nature of the study and the use of semistructured questionnaires, both of which might have biased the responses of women, who might have wanted to please the interviewers with favorable responses. Evaluating the expectations of ethical conduct after delivery exposed the study to recall bias. Also, the fact that focus-group discussions were not done excluded a detailed evaluation of the feelings of patients. Finally, the choice of a highly specific patient population means that the findings cannot be generalized to the general patient population in this area.

\section{Conclusion}

We conclude that most obstetric patients in the urban centers studied valued the ethical aspects of care and that levels of expectations were high. The current levels of adherence to ethical principles by doctors are encouraging, although they fall short of the expectations of patients. There is a need, therefore, for obstetricians to do more to meet the ethical expectations of patients, in this study population. The findings of this study suggest that medical ethics could become an important aspect of obstetric care in Nigeria as literacy levels and female empowerment improve among the population. Undergraduate and postgraduate medical schools should therefore develop curriculum-based training on medical ethics for doctors and medical students. Hospital policy makers need to provide written and official guidelines for adherence to medical ethical principles during obstetric care, including a more elaborate process for obtaining informed consent for surgeries. We recommend a further study on a general patient population in this area, to determine the applicability of the findings in this study to the general patient population in this resource-constrained setting.

\section{Acknowledgments}

We acknowledge the contributions of the Labor ward staff of the study hospitals as well as Drs Blanche Ngaitu, Emeka Onyia, Emeka Okonkwo, Ugochukwu Ezenyirioha,
Sunday Mba, and Chioma Emegoakor, who all assisted with the data collection for this study.

\section{Disclosure}

The authors declare no conflicts of interest in this work.

\section{Reference}

1. Medical and Dental Council of Nigeria [MDCN]. Code on Medical Ethics in Nigeria: Rules of Professional Conduct for Medical and Dental Practitioners. Lagos: MDCN; 2004.

2. Olweny C. Bioethics in developing countries: ethics of scarcity and sacrifice. J Med Ethics. 1994;20(3):169-174.

3. Ezeome ER, Marshall PA. Informed consent practices in Nigeria. Dev World Bioeth. 2009;9(3):138-148.

4. Agu KA. Informed consent policy and surgeons in South East Nigeria Nigeria J Surg. 2003;39-41.

5. Ogundiran TO, Adebamowo CA. Surgeons' opinions and practice of informed consent in Nigeria. $J$ Med Ethics. 2010;36(12):741-745.

6. Irabor DO, Omonzejele P. Local attitudes, moral obligation, customary obedience and other cultural practices: their influence on the process of gaining informed consent for surgery in a tertiary institution in a developing country. Dev World Bioeth. 2009;9(1):34-42.

7. Osamor PE, Kass N. Decision-making and motivation to participate in biomedical research in southwest Nigeria. Dev World Bioeth. 2012;12(2):87-95.

8. Onah HE, Okaro JM, Umeh U, Chigbu CO. Maternal mortality in health institutions with emergency obstetric care facilities in Enugu State, Nigeria. J Obstet Gynaecol. 2005;25(6):569-574.

9. Joffe S, Manocchia M, Weeks JC, Cleary PD. What do patients value in their hospital care? An empirical perspective on autonomy centred bioethics. J Med Ethics. 2003;29(2):103-108.

10. Osime OC, Okojie O, Osadolor F, Mohammed S. Current practices and medico-legal aspects of pre-operative consent. East Afr Med J. 2004;81(7):331-335.

11. Bako B, Umar N, Garba N, Khan N. Informed consent practices and its implication for emergency obstetrics care in azare, north-eastern Nigeria. Ann Med Health Sci Res. 2011;1(2):149-157.

12. Fadare JO. Some ethical issues in the prenatal diagnosis of sickle cell anemia. Annals of Ibadan Postgrad Med. 2009;7(2):26-28.

13. Adudu OP, Adudu OG. Therapeutic non-disclosure of adverse health information to an obstetric patient: case report. East Afr Med J. 2008;85(5):253-256.

14. National Population Commission (NPC) [Nigeria] and ICF Macro. Nigeria Demographic and Health Survey 2008. Abuja: National Population Commission; 2009.

15. Beauchamp TL, Childress JF. Principles of Biomedical Ethics. 6th ed. Oxford: Oxford University Press; 2009.

16. Chung GS, Lawrence RE, Curlin FA, Arora V, Meltzer DO. Predictors of hospitalised patients' preferences for physician-directed medical decision-making. J Med Ethics. 2012;38(2):77-82.

17. Cetin M, Ucar M, Güven T, Atac A, Ozer M. What do patients expect from their physicians? Qualitative research on the ethical aspects of patient statements. J Med Ethics. 2012;38(2):112-116. 


\title{
Supplementary figure
}

AN ASSESSMENT OF PATIENTS' VIEWS ON DOCTORS' COMPLIANCE WITH ETHICAL PRINCIPLES IN THE MANAGEMENT OF WOMEN UTILISING MATERNITY SERVICES IN TERTIARY HOSPITALS IN SOUTH EAST NIGERIA

\section{SECTION A: BIODATA}

\section{QUESTIONNAIRE}

\author{
i. Age (years).
}

ii. Occupation

iii. Educational level

iv. Residence

iv. Religion (denomination)

v. Tribe

vi. Number of previous deliveries

vii. Mode of delivery in index pregnancy

\section{SECTION B: GENERAL PERCEPTION OF DOCTORS' CONDUCT}

i. Was the conduct of doctors an important consideration in your choice of where to receive maternity care? Tick Yes or No

ii. How do you rate the importance of respectful and dignified handling by doctors during your care in this pregnancy and delivery? Tick only one as appropriate: (a) very important, (b) moderately important, (c) important, (d) unimportant, (e) very unimportant

iii. Do you consider free communication between women and doctors during maternity as an important aspect of your care during this pregnancy and delivery? Tick Yes or No

\section{SECTION C: EXPECTATIONS OF ETHICAL CONDUCT}

Which of these are conducts which you expect doctors to adhere to when looking after pregnant women? Tick Yes or No

a. Asking for and respecting the opinion of the patient in every decision regarding her investigation and treatment YES NO

b. Consideration and respect for the religious beliefs of the patient YES NO

c. Consideration of the ability of the patient to pay in choosing investigations and treatment YES NO

d. Strictly ensuring that no physical, emotional pr psychological harm is done to the patient in the course of her care YES NO

e. Ensuring that every aspect of her care is meant to do good to the patient YES NO

f. Having romantic relationship with the patient YES NO

g. Soliciting money or donations from the patient YES NO

h. Your personal contribution to decisions on your investigations and treatments YES NO

i. Being attended to on "first come, first seen" basis YES NO

j. Being seen only when there is a female chaperone YES NO

k. Respect for your emotional feelings in the course of your care YES NO

I. Respect for your privacy including the confidentiality of your case records YES NO

\section{SECTION D: EXPERIENCES OF ETHICAL CONDUCT/MISCONDUCT}

1. List all types of ethical/moral misconduct that you have observed among your doctors during your care in this pregnancy and delivery

2. Which of these have you experienced in the course of your care in this pregnancy? Tick Yes or No
a. Being attended to in the presence of too many people without respect for your privacy YES NO
b. Being examined alone by a doctor without the presence of a chaperone YES NO
c. Having investigation and treatment without asking for your opinion about them YES NO
d. Having investigation or treatment without having them explained to you YES NO
e. Not being talked to regarding what the doctor found out on your assessment each day of your visit YES NO
f. Demand for romantic or sexual relationship from your doctor YES NO 
g. Demand for monetary reward from your doctor before being treated or after treatment YES NO

h. Being touched inappropriately by your doctor YES NO

i. Verbal abuse from your doctor YES NO

\section{SECTION D: INFORMED CONSENT FOR CESAREAN SECTION}

(This section is for only those who had cesarean section.)

Which of the following did your doctor offer you before you had your operation? Tick Yes or No

Detailed explanation of indication for cesarean section

Yes

No

Detailed explanation of short term maternal risks associated with cesarean delivery such as anesthetic risks, primary hemorrhage, injury to bladder or ureters, infection, deep vein thrombosis

Yes

No

Detailed explanation of long term maternal risks associated with cesarean section such as higher risks for placenta previa and uterine rupture in subsequent pregnancies, higher need for subsequent cesarean section

Yes

No

Explanation of the surgery itself including the types of abdominal incision, duration of surgery, type of anesthesia

Yes

No

Explanation of the process of recovery from surgery such as pains, initial restriction of movement, initial restriction of oral feeding

Yes

No

Explanation of costs of surgery

Yes

No

SECTION E: RATING OF THE ETHICAL PRACTICES OF DOCTORS

How do you rate the implementation of the following ethical practices in this hospital in the course of your care in this pregnancy? Tick as appropriate

\begin{tabular}{|c|c|c|c|c|c|}
\hline \multirow[t]{2}{*}{ Ethical practice } & \multicolumn{5}{|l|}{ RATING } \\
\hline & Excellent & Very good & Good & Poor & Very poor \\
\hline \multicolumn{6}{|l|}{ Privacy during interview and examination } \\
\hline \multicolumn{6}{|l|}{$\begin{array}{l}\text { Physical examination in the presence } \\
\text { of a chaperone each time }\end{array}$} \\
\hline \multicolumn{6}{|l|}{$\begin{array}{l}\text { Asking your opinion on investigations } \\
\text { and treatment before prescribing them }\end{array}$} \\
\hline \multicolumn{6}{|l|}{$\begin{array}{l}\text { Explaining investigations and treatment } \\
\text { to you in a way that you could understand them }\end{array}$} \\
\hline \multicolumn{6}{|l|}{$\begin{array}{l}\text { Explaining the findings of your examination } \\
\text { and your diagnosis clearly to you }\end{array}$} \\
\hline \multicolumn{6}{|l|}{$\begin{array}{l}\text { Giving you counseling personally and obtaining } \\
\text { your consent before an HIV test }\end{array}$} \\
\hline \multicolumn{6}{|l|}{$\begin{array}{l}\text { Asking if you can pay for chosen test or treatment } \\
\text { and offering you alternatives in case you are } \\
\text { not able to pay }\end{array}$} \\
\hline \multicolumn{6}{|c|}{$\begin{array}{l}\text { Explaining the benefits and drawbacks of different tests } \\
\text { and treatments available }\end{array}$} \\
\hline $\begin{array}{l}\text { Explaining the benefits as well as the dangers } \\
\text { of any operation you had }\end{array}$ & & & & & \\
\hline
\end{tabular}

Figure SI The study questionnaire. 
International Journal of Women's Health

Dovepress

\section{Publish your work in this journal}

The International Journal of Women's Health is an international, peerreviewed open-access journal publishing original research, reports, editorials, reviews and commentaries on all aspects of women's healthcare including gynecology, obstetrics, and breast cancer. The manuscript management system is completely online and includes Visit http://www.dovepress.com/testimonials.php to read real quotes from published authors.

Submit your manuscript here: http://www.dovepress.com/international-journal-of-womens-health-journal 